\title{
Prevalence and clinical implications of bronchiectasis in patients with overlapping asthma and chronic rhinosinusitis: a single-center prospective study
}

\author{
Haiyan Sheng ${ }^{1 \dagger}$, Xiujuan Yao ${ }^{1 \dagger}$, Xiangdong Wang ${ }^{2,3}$, Yuhong Wang ${ }^{1}$, Xiaofang Liu ${ }^{1 *}$ and Luo Zhang ${ }^{2,3^{*}}$
}

\begin{abstract}
Background: As a typical "united airway" disease, asthma-chronic rhinosinusitis (CRS) overlap has recently drawn more attention. Bronchiectasis is a heterogeneous disease related to a variety of diseases. Whether bronchiectasis exists and correlates with asthma-CRS patients has not been fully elucidated. The purpose of the study was to explore the presence and characteristics of bronchiectasis in patients with overlapping asthma and CRS.

Methods: This report describes a prospective study with consecutive asthma-CRS patients. The diagnosis and severity of bronchiectasis were obtained by thorax high-resolution computed tomography (HRCT), the Smith radiology scale and the Bhalla scoring system. CRS severity was evaluated by paranasal sinus CT and the Lund-Mackay (LM) scoring system. The correlations between bronchiectasis and clinical data, fraction of exhaled nitric oxide, peripheral blood eosinophil counts and lung function were analyzed.

Results: Seventy-two (40.91\%) of 176 asthma-CRS patients were diagnosed with bronchiectasis. Asthma-CRS patients with overlapping bronchiectasis had a higher incidence rate of nasal polyps (NPs) $(P=0.004)$, higher LM scores $(P=0.044)$, higher proportion of $\geq 1$ severe exacerbation of asthma in the last 12 months $(P=0.003)$, lower postbronchodilator forced expiratory volume in one second $\left(F E V_{1}\right) \%$ predicted $(P=0.006)$, and elevated peripheral blood eosinophil counts $(P=0.022)$. Smith and Bhalla scores were shown to correlate positively with NPs and negatively with $\mathrm{FEV}_{1} \%$ predicted and body mass index. Cutoff values of $\mathrm{FEV}, \%$ predicted $\leq 71.40 \%$, peripheral blood eosinophil counts $>0.60 \times 10^{9} / \mathrm{L}$, presence of NPs, and $\geq 1$ severe exacerbation of asthma in the last 12 months were shown to differentiate bronchiectasis in asthma-CRS patients.
\end{abstract}

Conclusions: Bronchiectasis commonly overlaps in asthma-CRS patients. The coexistence of bronchiectasis predicts a more severe disease subset in terms of asthma and CRS. We suggest that asthma-CRS patients with NPs, severe

\footnotetext{
*Correspondence: xfliutrhos@163.com; dr.luozhang@139.com

${ }^{\dagger}$ Haiyan Sheng and Xiujuan Yao have contributed equally to this article

${ }^{1}$ Department of Respiratory and Critical Care Medicine, Beijing

Tongren Hospital, Capital Medical University, No. 1, Dongjiao Minxiang,

Dongcheng District, Beijing 100730, China

${ }^{3}$ Key Laboratory of Otolaryngology Head and Neck Surgery of Ministry

of Education of China, Beijing Institute of Otolaryngology, No. 17, Hougou

Hutong, Dongcheng District, Beijing 100005, China

Full list of author information is available at the end of the article
}

(c) The Author(s) 2021. Open Access This article is licensed under a Creative Commons Attribution 4.0 International License, which permits use, sharing, adaptation, distribution and reproduction in any medium or format, as long as you give appropriate credit to the original author(s) and the source, provide a link to the Creative Commons licence, and indicate if changes were made. The images or other third party material in this article are included in the article's Creative Commons licence, unless indicated otherwise in a credit line to the material. If material is not included in the article's Creative Commons licence and your intended use is not permitted by statutory regulation or exceeds the permitted use, you will need to obtain permission directly from the copyright holder. To view a copy of this licence, visit http://creativecommons.org/licenses/by/4.0/. The Creative Commons Public Domain Dedication waiver (http://creativeco mmons.org/publicdomain/zero/1.0/) applies to the data made available in this article, unless otherwise stated in a credit line to the data. 
airflow obstruction, eosinophilic inflammation, and poor asthma control should receive HRCT for the early diagnosis of bronchiectasis.

Keywords: Asthma, Bronchiectasis, Chronic rhinosinusitis, Nasal polyps

\section{Background}

The "united airways" concept indicates that upper and lower airway diseases often coexist and share similar pathogenic mechanisms, and asthma-chronic rhinosinusitis (CRS) overlap is a typical "united airways" disease [1-3]. It was shown that CRS was associated with more severe asthma, especially in CRS with nasal polyp (NP) patients [2, 4].

Bronchiectasis is a heterogeneous disease characterized by permanent and irreversible destruction and dilatation of the bronchial wall induced by chronic airway inflammation [5]. The overlap of asthma and bronchiectasis in the same patients has been described in several observations $[6,7]$. Asthma can be diagnosed in approximately $50 \%$ of patients with bronchiectasis $[8,9]$; in turn, bronchiectasis has been diagnosed in $3-47 \%$ of patients with asthma $[6,10]$. The coexistence of asthma and bronchiectasis may indicate a potentially specific disease phenotype with distinct clinical features and therapeutic options [11]. The correlation between CRS with NPs (CRSwNPs) and bronchiectasis has also been reported [12]. The prevalence of CRS in patients with bronchiectasis is $45-77 \%$ [3, 12-14]. Bronchiectasis patients with CRS are shown to have significantly more exacerbations and worse quality of life than bronchiectasis patients without CRS involvement [14], indicating that the coexistence of CRS in bronchiectasis patients represents a more severe disease subset.

Traditionally, bronchiectasis is characterized by neutrophilic inflammation and closely linked to persistent bacterial infection [5]. Nevertheless, the inflammatory characteristics of bronchiectasis in asthma or CRS were controversial in previous studies. Some records indicated that bronchiectasis presented eosinophilic inflammation in asthma or CRS patients $[15,16]$, while others drew the opposite conclusion [7, 17]. Given these discrepancies, it is therefore necessary to investigate the inflammatory characteristics of bronchiectasis in asthma-CRS patients.

Although there have been several studies involving the association of bronchiectasis with asthma or CRS, to date, whether bronchiectasis exists and correlates with asthma-CRS patients has not been fully elucidated. In this study, we aimed to assess the prevalence, inflammatory characteristics, and clinical implications of bronchiectasis in a prospective cohort of asthma-CRS patients.

\section{Methods}

\section{Study and participants}

This report describes a prospective study. Outpatients diagnosed with asthma-CRS were consecutively enrolled at the Department of Respiratory Medicine and Otorhinolaryngology of Beijing Tongren Hospital from Jan 2016 to Dec 2019. Asthma diagnosis was made according to the Global Initiative for Asthma (GINA) criteria [18]: (1) a definite clinical history of asthmatic symptoms; and (2) hyperbronchodilator reversibility with an increase in forced expiratory volume in one second $\left(\mathrm{FEV}_{1}\right)>12 \%$ and $>200 \mathrm{~mL}$ from baseline and/or airway hyperresponsiveness with a decrease in $\mathrm{FEV}_{1}$ from baseline of $\geq 20 \%$ with standard doses of methacholine. All participants were stable for at least 1 month without oral corticosteroids. Severe asthma was defined as an uncontrolled condition despite step 4 or 5 therapy and treatment of contributory factors or worsened when high-dose treatment was decreased according to the GINA criteria [18]. Severe exacerbation of asthma was defined as an asthma attack that needed emergency department attendance, hospitalization, or the need for oral corticosteroids [18]. CRS was diagnosed by the guidelines of the European Position Paper on Rhinosinusitis and Nasal Polyps 2020 [3]. Patients were excluded if any of the following applied: (1) diagnosis of bronchiectasis prior to asthma; (2) chronic obstructive pulmonary disease (COPD) or any other significant respiratory diseases; (3) pneumonia or measles in childhood, primary ciliary dysfunction, tuberculosis or other diseases that can interfere with bronchiectasis; (4) pregnancy; (5) cancer; (6) severe heart failure; and (7) smoking index $>20$ pack-years.

Clinical data were collected, while peripheral blood eosinophil counts, serum immunoglobulin E (IgE) levels, fraction of exhaled nitric oxide (FeNO), lung function, paranasal sinus $\mathrm{CT}$ and thorax high-resolution $\mathrm{CT}$ (HRCT) were examined and analyzed.

This study complied with the Declaration of Helsinki and was approved by the Ethics Committee of Beijing Tongren Hospital, Capital Medical University (approval number: TRECKY2013-KS-37). Written informed consent was obtained from all recruited patients.

\section{FeNO analysis}

Patients were instructed to exhale at a flow rate of $50 \mathrm{~mL} / \mathrm{s}$ through a disposable mouthpiece by the NIOX electrochemical analyzer (Aerocrine, Sweden) [19]. 
Table 1 Baseline patient characteristics $(n=176)$

\begin{tabular}{|c|c|}
\hline Characteristics & Values \\
\hline Male sex, n (\%) & $89(50.57)$ \\
\hline Age, y & $53.90 \pm 14.26(51.78-56.03)$ \\
\hline $\mathrm{BMI}, \mathrm{kg} / \mathrm{m}^{2}$ & $24.56 \pm 3.94(23.98-25.15)$ \\
\hline Positive smoking status ${ }^{\mathrm{a}}, \mathrm{n}(\%)$ & $55(31.25)$ \\
\hline Smoking index ${ }^{b}$, pack-years & $10.00(8.00,14.00)$ \\
\hline Duration of asthma, y & $6.50(2.00,18.00)$ \\
\hline NPs, n (\%) & $82(46.59)$ \\
\hline Prior sinus surgery, n (\%) & $34(19.32)$ \\
\hline Allergic rhinitis, n (\%) & $112(63.64)$ \\
\hline Atopic dermatitis, n (\%) & $14(7.95)$ \\
\hline Gastroesophageal reflux disease, n (\%) & $14(7.95)$ \\
\hline ICS dose (fluticasone equivalent), $\mu \mathrm{g} / \mathrm{d}$ & $320.00(160.00,320.00)$ \\
\hline Severe asthma, n (\%) & $26(14.77)$ \\
\hline $\begin{array}{l}\geq 1 \text { severe exacerbation of asthma in the } \\
\text { last } 12 \text { months, } \mathrm{n}(\%)\end{array}$ & $54(30.68)$ \\
\hline$\geq 1$ pneumonia in the last 12 months, $n(\%)$ & $51(28.98)$ \\
\hline Peripheral blood eosinophil counts, $\times 10^{9} / \mathrm{L}$ & $0.37(0.20,0.70)$ \\
\hline FeNO, ppb & $36.50(18.00,66.00)$ \\
\hline Total lgE, IU/mL & $177.00(48.83,356.50)$ \\
\hline Atopy, n (\%) & $91(51.70)$ \\
\hline Postbronchodilator $\mathrm{FEV}_{1} \%$ predicted, $\%$ & $79.10 \pm 19.91(76.13-82.06)$ \\
\hline LM scores & $10.00(6.00,17.00)$ \\
\hline Bronchiectasis in HRCT, $\mathrm{n}(\%)$ & $72(40.91)$ \\
\hline
\end{tabular}

Parametric data are expressed as the mean \pm SD (95\% Cl); nonparametric data are expressed as the median (interquartile range). ICS, inhaled corticosteroid; $2 \mu \mathrm{g}$ beclomethasone $=2 \mu \mathrm{g}$ budesonide $=1 \mu \mathrm{g}$ fluticasone

$B M I$ body mass index, NPs nasal polyps, $F E V$, forced expiratory volume in $1 \mathrm{~s}$, FeNO fractional exhaled nitric oxide, lgE immunoglobulin E, LM Lund-Mackay

a Positive smoking status included ex-or current-smokers

${ }^{\mathrm{b}}$ Smoking history in patients with positive smoking status

Measurements were performed at least three times, and the average was calculated for analysis.

\section{Asthma assessment with spirometry}

Postbronchodilator $\mathrm{FEV}_{1}$ and forced vital capacity (FVC) were measured by a spirometer (Jaeger, Germany). The procedure was performed in accordance with current ATS/ERS guidelines [20].

\section{Radiological diagnosis and severity assessment of bronchiectasis by using HRCT}

Chest HRCT (Phillips Company, Amsterdam, the Netherlands) images were obtained in full inspiration with $1-\mathrm{mm}$ collimation. A broncho-arterial ratio $>1$ in HRCT images was diagnosed as bronchiectasis radiologically [21]. Smith scores were used to estimate the extent of bronchiectasis in each lobe [22]: 0 if there was no evidence of bronchiectasis, and $1-4$ if $<25 \%, 25-49 \%$, $50-74 \%$ and $\geq 75 \%$ of the bronchi were abnormal, respectively. The lingula was graded as a separate lobe, and the maximum possible score was 24. Patients with Smith scores $\geq 3$ were assigned to the bronchiectasis group as previously described [23]. Meanwhile, the Bhalla scoring system was used to estimate the severity of bronchiectasis in each lobe [24]: 0 if no involvement, and 1-3 if the broncho-arterial ratio was $<2,2-3$, and $>3$, respectively. Two thoracic radiologists ranked the Smith and Bhalla scores independently, and the final score of each lobe was the average.

\section{CRS analysis using paranasal sinus CT}

Patients received paranasal sinus CT examination (Phillips Company), the LM staging system was applied to rank the severity of sinusitis, and the average was scored by two independent radiologists blinded to the clinical status [25]. The sinus groups included the maxillary, frontal, sphenoidal, anterior ethmoidal, and posterior ethmoidal sinuses. Each sinus group was subsequently assigned a numeric grade: 0 , if no abnormality; 1 , if partial opacification; and 2, if total opacification. The condition of the ostiomeatal complex was simply scored as 0 if not obstructed or 2 if obstructed. The total score range was from 0 to 24 [25].

\section{Statistical analysis}

The mean \pm standard deviation (SD) with $95 \%$ confidence interval $(\mathrm{CI})$, median (interquartile range) and frequencies/percentages were used to show parametric, nonparametric and categorical variables, respectively. The unpaired $t$ test or Mann-Whitney $U$ test was used to determine the significance of continuous variables as appropriate. The chi-square test was used to determine the significance of categorical variables. Line regression was used to test the correlation between the severity of bronchiectasis and the clinical parameters. Multivariate logistic regression and multivariate linear regression were used to calculate coefficients or odds ratios as appropriate. Statistical analysis was carried out by using SPSS 21.0 software. A $P$ value $<0.05$ was considered to be significant.

The receiver operating characteristic (ROC) curve, area under the curve (AUC), and the optimal cutoff value of postbronchodilator $\mathrm{FEV}_{1} \%$ predicted, $\geq 1$ severe exacerbation of asthma in the last 12 months, peripheral blood eosinophil counts and postbronchodilator $\mathrm{FEV}_{1} \%$ predicted for bronchiectasis were calculated according to the method described by Hanley and McNeil [26]. As continuous test variables, peripheral blood eosinophil counts and postbronchodilator $\mathrm{FEV}_{1} \%$ predicted were converted to dichotomous state variables based on the ideal cutoff values. Subsequently, dichotomous state variables of peripheral blood eosinophil counts, postbronchodilator $\mathrm{FEV}_{1} \%$ predicted, NP, and $\geq 1$ severe exacerbation of 
Table 2 Comparison of characteristics of patients with bronchiectasis versus nonbronchiectasis

\begin{tabular}{|c|c|c|c|}
\hline Variables & Nonbronchiectasis group $(n=104)$ & Bronchiectasis group $(n=72)$ & $P$ Value \\
\hline Male sex, n (\%) & $51(49.04)$ & $38(52.78)$ & 0.626 \\
\hline Age, y & $53.28 \pm 14.66(50.43-56.13)$ & $54.81 \pm 13.71(51.58-58.03)$ & 0.487 \\
\hline $\mathrm{BMI}, \mathrm{kg} / \mathrm{m}^{2}$ & $24.87 \pm 3.61(24.17-25.57)$ & $24.12 \pm 4.37(23.09-25.14)$ & 0.213 \\
\hline Positive smoking status ${ }^{\mathrm{a}}, \mathrm{n}(\%)$ & $31(29.81)$ & $24(33.33)$ & 0.620 \\
\hline Smoking index ${ }^{b}$, pack-years & $10.00(8.00,14.00)$ & $8.00(6.25,13.50)$ & 0.113 \\
\hline Duration of asthma, y & $5.50(1,12.75)$ & $8.00(2.00,20.00)$ & 0.171 \\
\hline NPs, n (\%) & $35(33.65)$ & $40(55.56)$ & 0.004 \\
\hline Prior sinus surgery, n (\%) & $16(15.38)$ & $18(25.00)$ & 0.112 \\
\hline Allergic rhinitis, n (\%) & $63(60.58)$ & $49(68.06)$ & 0.311 \\
\hline Atopic dermatitis, n (\%) & $11(10.58)$ & $3(4.17)$ & 0.122 \\
\hline Gastroesophageal reflux disease, n (\%) & $9(8.65)$ & $5(6.94)$ & 0.680 \\
\hline ICS dose (fluticasone equivalent), $\mu \mathrm{g} / \mathrm{d}$ & $320.00(160.00,320.00)$ & $285.00(160.00,320.00)$ & 0.713 \\
\hline Severe asthma, n (\%) & $11(10.58)$ & $15(20.83)$ & 0.059 \\
\hline $\begin{array}{l}\geq 1 \text { severe exacerbation of asthma in the last } \\
12 \text { months, } n(\%)\end{array}$ & $23(22.12)$ & $31(43.06)$ & 0.003 \\
\hline$\geq 1$ pneumonia in the last 12 months, $\mathrm{n}(\%)$ & $27(25.96)$ & $24(33.33)$ & 0.289 \\
\hline Peripheral blood eosinophil counts, $\times 10^{9} / \mathrm{L}$ & $0.32(0.15,0.58)$ & $0.44(0.23,0.90)$ & 0.022 \\
\hline FeNO, ppb & $32.00(18.00,61.75)$ & $44.00(23.00,74.75)$ & 0.056 \\
\hline Total lgE, IU/mL & $135.50(48.10,285.50)$ & $232.00(56.75,525.25)$ & 0.044 \\
\hline Atopy, n (\%) & $57(54.81)$ & $34(47.22)$ & 0.322 \\
\hline Postbronchodilator $\mathrm{FEV}_{1} \%$ predicted, $\%$ & $83.09 \pm 16.47(79.89-86.30)$ & $73.32 \pm 22.94(67.93-78.71)$ & 0.006 \\
\hline LM scores & $9.00(6.00,15.75)$ & $11.50(7.25,18.00)$ & 0.044 \\
\hline Smith scores of bronchiectasis & & $7.56 \pm 3.46(6.75-8.37)$ & \\
\hline Bhalla scores of bronchiectasis & & $3.97 \pm 1.50(3.62-4.32)$ & \\
\hline
\end{tabular}

Parametric data are expressed as the mean \pm SD (95\% Cl); nonparametric data are expressed as the median (interquartile range)

$B M I$ body mass index, NPs nasal polyps, FEV forced expiratory volume in $1 \mathrm{~s}, I C S$ inhaled corticosteroid, FeNO fractional exhaled nitric oxide, IgE immunoglobulin E, LM Lund-Mackay

${ }^{\text {a }}$ Positive smoking status included ex- and current smokers

b Smoking history in patients with positive smoking status

asthma in the last 12 months as covariates established a multiple logistic regression and were subsequently conducted to acquire a predictive equation for a combined model. ROC curves were then determined for the 5 dichotomous state variables. Finally, using the 5 dichotomous state variables, differentiation of bronchiectasis was performed by comparing their AUCs using MedCalc software.

\section{Results}

\section{Patient characteristics}

A total of 176 patients (mean age, $53.90 \pm 14.26$ years) were included in the study and $89(50.57 \%)$ were males. The median asthma duration was $6.50(2.00,18.00)$ years. Fifty-four $(30.68 \%)$ patients experienced at least one severe exacerbation of asthma in the last 12 months. A total of $82(46.59 \%)$ patients suffered from NPs. Bronchiectasis was present in 72 (40.91\%) patients. Patient characteristics are summarized in Table 1.

\section{Characteristics of asthma-CRS patients overlapping with bronchiectasis}

The patients were allocated into 2 different subgroups, asthma-CRS patients with and without bronchiectasis, for further comparison. As shown in Table 2 and Figs. 1 and 2, patients with bronchiectasis showed a higher frequency of severe exacerbation of asthma in the last 12 months $(P=0.003)$, elevated peripheral blood eosinophil counts $(P=0.022)$ and total IgE levels $(P=0.044)$, lower $\mathrm{FEV}_{1} \%$ predicted $(P=0.006)$, higher LM scores $(P=0.044)$ and increased occurrence rates of NPs $(P=0.004)$. There were no observed differences in sex, age, smoking status, sinus surgery history, prevalence of atopic diseases, inhaled corticosteroid (ICS) dose, or ratio of $\geq 1$ pneumonia in the last 12 months between the two groups. 

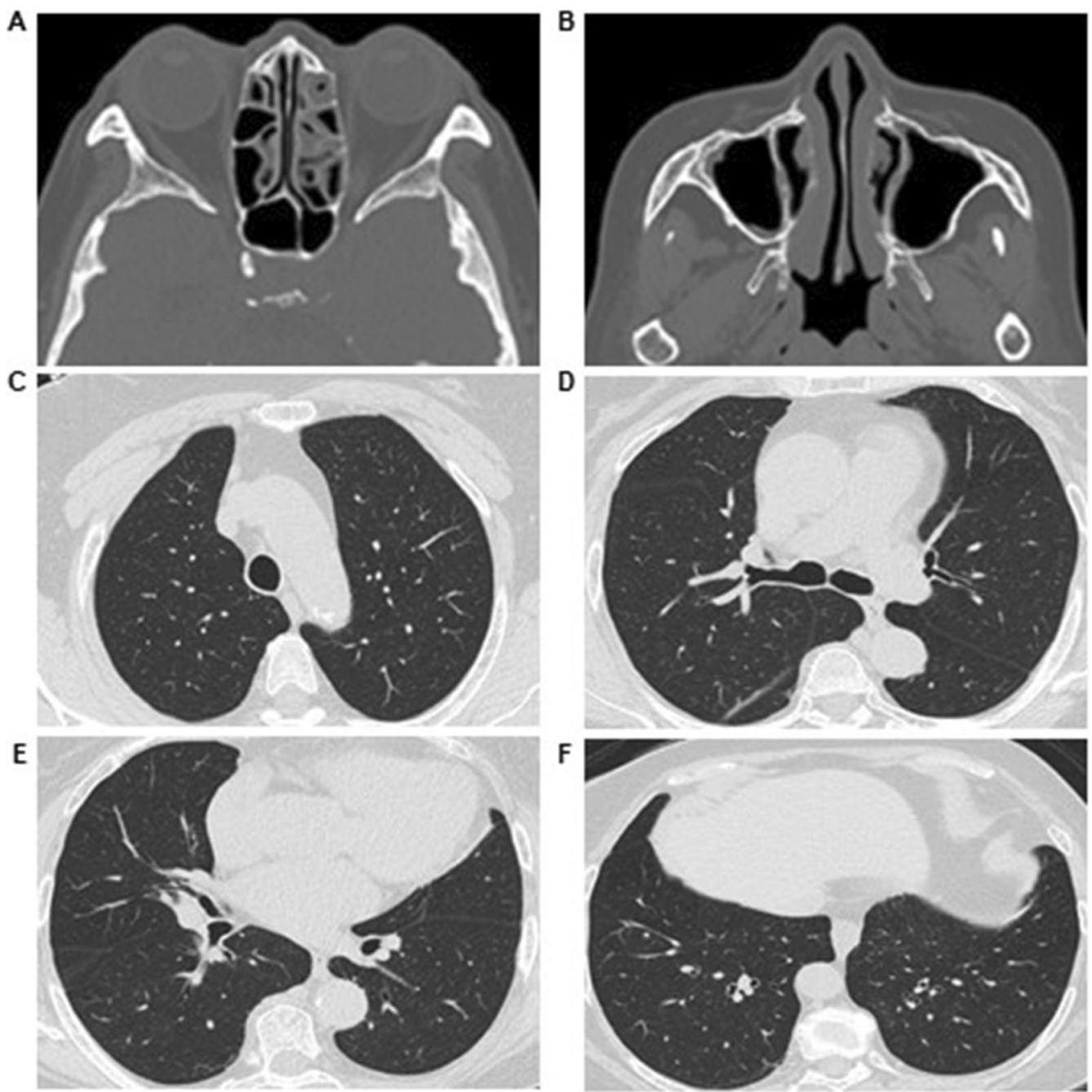

Fig. 1 Typical imaging findings of the nonbronchiectasis group. A 65-year-old female suffered from asthma for 3 years and CRS for 1 year. A, B Paranasal sinus CT imaging revealing CRS involving maxillary and ethmoidal sinuses without the existence of nasal polyps. C-F Lung windows of HRCT were normal

\section{Coexistence of bronchiectasis correlates with disease severity in asthma-CRS patients}

Logistic analysis indicated that the presence of bronchiectasis was positively correlated with NPs (OR 2.79; $95 \%$ CI 1.43-5.46), $\geq 1$ severe exacerbation of asthma in the last 12 months (OR 2.14; 95\% CI 1.02-4.51) and peripheral blood eosinophil counts (OR 2.60; 95\% CI 1.19$5.67)$ and negatively associated with postbronchodilator $\mathrm{FEV}_{1} \%$ predicted (OR 0.98; 95\% CI 0.96-1.00) (Table 3).

ROC curves were created to assess the diagnostic accuracy and optimal cutoff values of NPs, $\geq 1$ severe exacerbation of asthma in the last 12 months, postbronchodilator $\mathrm{FEV}_{1} \%$ predicted, peripheral blood eosinophil counts, and a combined model for bronchiectasis within the asthma-CRS patients (Fig. 3). The AUC values of NPs, $\geq 1$ severe exacerbation of asthma in the last 12 months, postbronchodilator $\mathrm{FEV}_{1} \%$ predicted and peripheral blood eosinophil counts in diagnosing bronchiectasis were 0.61 (95\% CI 0.53-0.68), 0.61 (95\% CI $0.53-0.68), 0.64$ (95\% CI $0.57-0.71)$ and 0.60 (95\% CI 0.53-0.67), respectively. Postbronchodilator $\mathrm{FEV}_{1} \%$ predicted at $71.40 \%$ exhibited the optimal sensitivity (51.39\%) and specificity (79.81\%), and peripheral blood eosinophil counts at $0.60 \times 10^{9} / \mathrm{L}$ exhibited the optimal sensitivity $(41.67 \%)$ and specificity $(77.88 \%)$ for predicting the diagnosis of bronchiectasis (Table 4).

The AUC of the combined model with postbronchodilator $\mathrm{FEV}_{1} \%$ predicted $\leq 71.40 \%$, peripheral blood eosinophil counts $>0.60 \times 10^{9} / \mathrm{L}$, the presence of NPs, and $\geq 1$ severe exacerbation of asthma in the last 12 months 

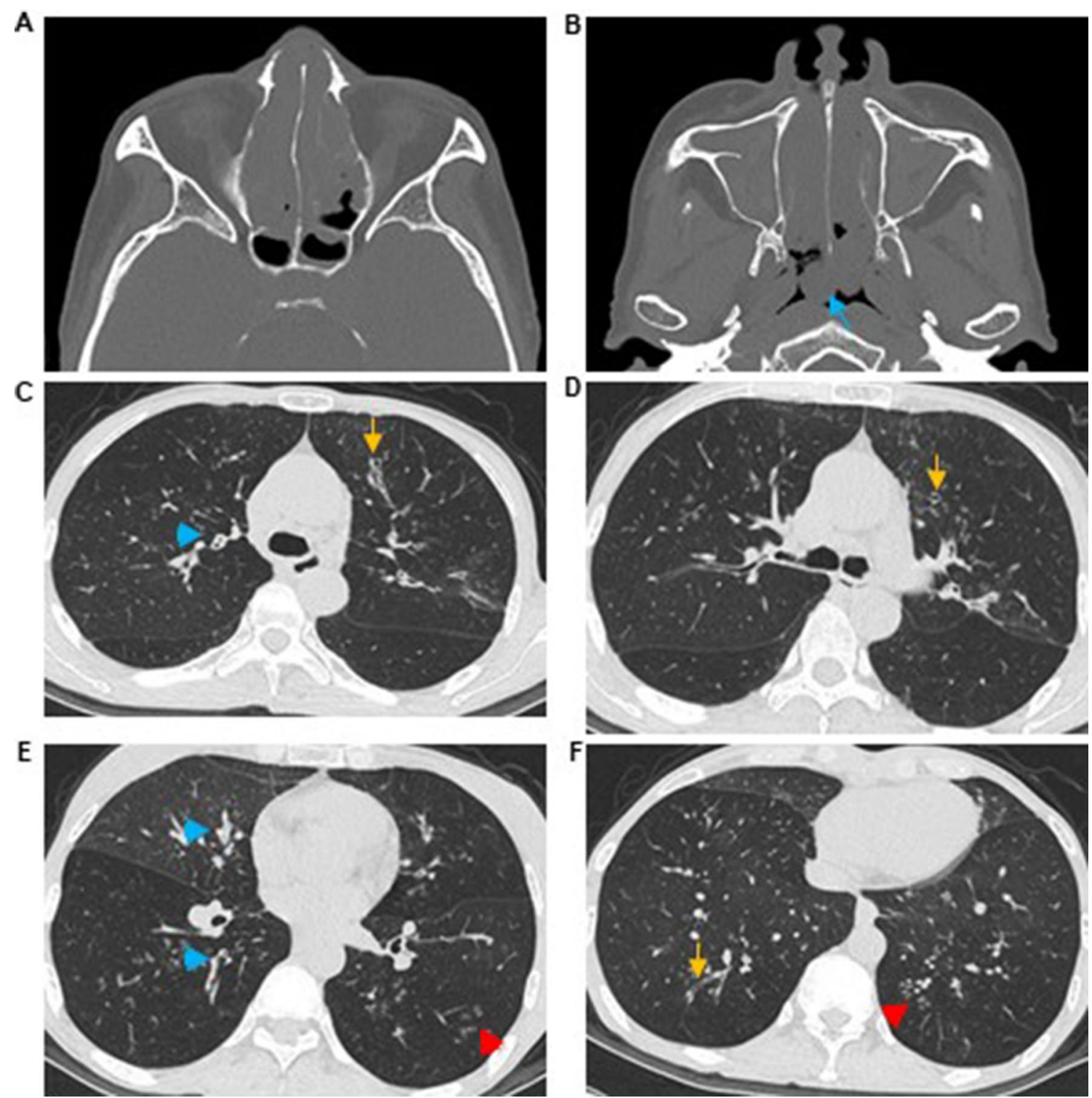

Fig. 2 Typical imaging findings of the bronchiectasis group. A 55-year-old female suffered from asthma for 30 years and CRS for 20 years and experienced one severe exacerbation of asthma in the last 12 months. A, B Paranasal sinus CT imaging revealing CRS involving the whole sinuses with the existence of nasal polyps (blue arrow). $\mathbf{C}-\mathbf{F}$ Lung windows of HRCT depicting extensive bronchiectasis (yellow arrow), with thickened bronchial walls (blue arrowhead) and the presence of a tree-in-bud pattern (red arrowhead)

Table 3 Logistic regression analyses for bronchiectasis

\begin{tabular}{llll}
\hline Variables & \multicolumn{3}{l}{$\begin{array}{l}\text { Bronchiectasis: logistic } \\
\text { regression }\end{array}$} \\
\cline { 2 - 4 } & OR & $\mathbf{9 5 \% ~ C l}$ & P value \\
\hline NPs & 2.79 & 1.43 to 5.46 & 0.003 \\
$\geq 1$ severe exacerbation of asthma in & 2.14 & 1.02 to 4.51 & 0.045 \\
$\quad \begin{array}{llll}\text { the last 12 months } \\
\text { Peripheral blood eosinophil counts }\end{array}$ & 2.60 & 1.19 to 5.67 & 0.016 \\
Postbronchodilator FEV $\%$ predicted & 0.98 & 0.96 to 1.00 & 0.039 \\
\hline
\end{tabular}

FEV 1 forced expiratory volume in $1 \mathrm{~s}$, NPs nasal polyps was 0.75 (95\% CI 0.68-0.81). The AUC of the combined model predicted better diagnostic accuracy than NPs, $\geq 1$ severe exacerbation of asthma in the last 12 months, postbronchodilator $\mathrm{FEV}_{1} \%$ predicted or peripheral blood eosinophil counts $(P<0.001)$.

\section{Extent and severity of bronchiectasis predict a more severe asthma-CRS subset}

Univariate analyses showed that Smith scores were associated with lower BMI $(P=0.049)$. Although not 
significant, Smith scores also correlated with $\mathrm{FEV}_{1} \%$ predicted $(P=0.051)$, NP occurrence $(P=0.088)$ and $\geq 1$ pneumonia in the last 12 months $(P=0.091)$ (Table 5 , Fig. 4A, B). On the other hand, Bhalla scores were significantly associated with lower BMI $(P=0.035)$, higher FeNO $(P=0.044)$, lower $\mathrm{FEV}_{1} \%$ predicted $(P=0.045)$ and a higher occurrence ratio of NPs $(P=0.026)$. Bhalla scores also correlated with higher LM scores $(P=0.060)$ and positive smoking status $(P=0.050)$, although these results were not significant (Table 6, Fig. 4C, D).

Multivariate linear regression showed that the Smith scores were positively correlated with NP occurrence ( $\beta$ coefficients: $1.74 ; 95 \%$ CI $0.250-3.24$ ) and negatively correlated with postbronchodilator $\mathrm{FEV}_{1} \%$ predicted $(\beta$ coefficients: $-0.04 ; 95 \% C I-0.07$ to -0.01$)$ and BMI ( $\beta$ coefficients: $-0.18 ; 95 \% C I-0.34$ to -0.01 ). Bhalla scores were positively correlated with NPs $(\beta$ coefficients: 1.11; $95 \% C I 0.45$ to 1.77$)$ and positive smoking status $(\beta$ coefficients: 0.73 ; $95 \%$ CI $0.03-1.44)$ and negatively correlated with postbronchodilator $\mathrm{FEV}_{1} \%$ predicted $(\beta$ coefficients: $-0.02 ; 95 \% C I-0.03$ to -0.00$)$ and BMI $(\beta$ coefficients: -0.08 ; $95 \%$ CI -0.16 to -0.00$)$ (Table 7).

\section{Discussion}

As a typical "united airways" disease, the asthma-CRS overlap has recently drawn the attention of respiratory physicians, otolaryngologists and allergists $[3,18,27]$. Bronchiectasis is a heterogeneous disease related to a variety of diseases. Whether bronchiectasis exists and correlates with asthma-CRS patients has not been fully elucidated. In this study, we summarized the prevalence of bronchiectasis in asthma-CRS patients, and furthermore, we analyzed the characteristics of a novel disease subset, bronchiectasis overlapping with asthma-CRS in the united airway.

Bronchiectasis is a chronic bronchial disorder characterized by permanent and irreversible destruction and dilatation of the bronchial wall leading to chronic airway inflammation and bacterial colonization $[5,8,21]$. When used to describe a disease, bronchiectasis includes a heterogeneous group of disorders that differ significantly in terms of etiological, clinical, radiological, functional and microbial features. Previous studies have revealed overlaps between bronchiectasis and chronic upper and lower airway diseases. Bronchiectasis has been reported in $3-47 \%$ of patients initially diagnosed with asthma $[6,10]$ and in approximately $5.5 \%$ of patients with CRS [1]. In our cohort, we found that $40.9 \%$ of asthma-CRS patients could also be codiagnosed with bronchiectasis (Table 1), indicating that bronchiectasis was popular in this group of patients.

Generally, bronchiectasis is primarily mediated by neutrophilic inflammation, which is closely linked to persistent bacterial infection [5]. In contrast, inflammatory cells are dominantly eosinophils in the pathogenesis of asthma and CRS $[3,18,28]$. We showed that the existence of bronchiectasis in asthma-CRS patients was associated with elevated peripheral blood eosinophil counts and IgE levels, indicating that the nature of the inflammatory pattern in bronchiectasis patients with asthma-CRS overlap is eosinophilic rather than neutrophilic. In line with our studies, previous studies also showed that elevated eosinophilic inflammation may be correlated with more severe remodeling in the large- to medium-sized airway, bronchial wall thickening, mucus plugging, and bronchiectasis in asthma patients [28, 29]. Steroid-dependent asthma is predominately mediated by eosinophilic airway inflammation and is more likely to be associated with bronchiectasis [30], indicating that eosinophilic airway inflammation is related to bronchiectasis formation in asthma patients. Similarly, recent data also found that peripheral eosinophil counts were elevated in patients with bronchiectasis and CRS [13]. Bronchiectasis may be induced by eosinophil infiltration and eosinophil-derived cationic proteins, lipid mediators, cytokines, chemokines, and growth factors [5]. Hence, we believe that ICS and eosinophilic targeted therapy (such as IL-5 antibody) are beneficial for the distinct disease subset with bronchiectasis-asthma-CRS overlapping in the same airway. However, in contrast with our study, Padilla-Galo et al. [15] found that bronchiectasis was related to lower levels of FeNO, which indicates a neutrophil infiltration pattern. Notably, the OR for FeNO in their results was 0.98 , close to 1 , indicating that the correlation was not strong. In addition, it is plausible that bronchiectasis in asthma-CRS patients correlates with both "eosinophilic-high" and "neutrophilic-high" inflammation patterns. Thus, precise, individualized treatment

\footnotetext{
(See figure on next page.)

Fig. 3 ROC curves to assess the diagnostic accuracy for bronchiectasis in asthma-CRS overlap patients. A ROC curve of NPs for assessing the diagnostic accuracy for bronchiectasis. B ROC curve of $\geq 1$ severe exacerbation of asthma in the last 12 months for assessing the diagnostic accuracy for bronchiectasis. C ROC curve of postbronchodilator $\mathrm{FEV}_{1} \%$ predicted for assessing the diagnostic accuracy for bronchiectasis. D ROC curve of peripheral blood eosinophil counts for assessing the diagnostic accuracy for bronchiectasis. E ROC curve of the combined model with postbronchodilator $\mathrm{FEV}_{1} \%$ predicted $\leq 71.4 \%$, peripheral blood eosinophil counts $>0.6 \times 10^{9} / \mathrm{L}, \mathrm{NPs}$, and $\geq 1$ severe exacerbation of asthma in the last 12 months for assessing the diagnostic accuracy for bronchiectasis. $\mathbf{F}$ ROC curves of the combined model, postbronchodilator FEV ${ }_{1} \%$ predicted $\leq 71.4 \%$, peripheral blood eosinophil counts $>0.6 \times 10^{9} / \mathrm{L}, \mathrm{NPs}$, and $\geq 1$ severe exacerbation of asthma in the last 12 months to assess the diagnostic accuracy for bronchiectasis
} 
A

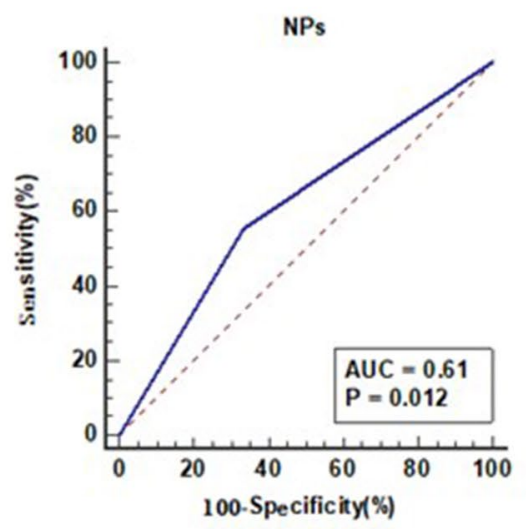

C

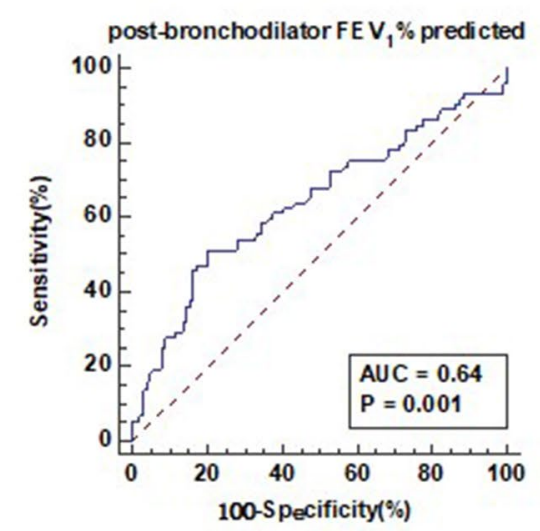

E

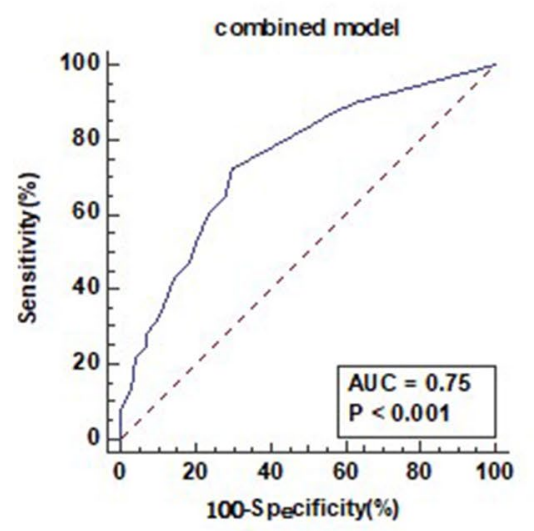

B

$\geqslant$ 1severe exacerbation of astheain the last 12 months

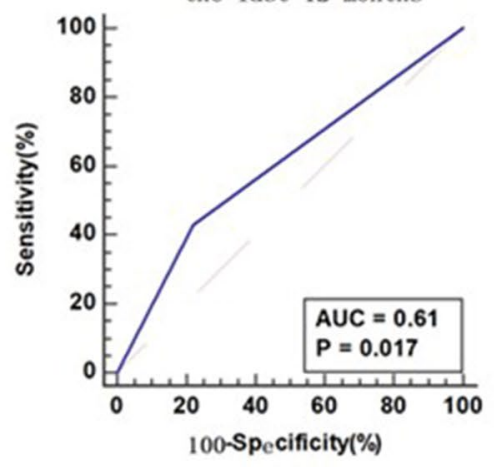

D

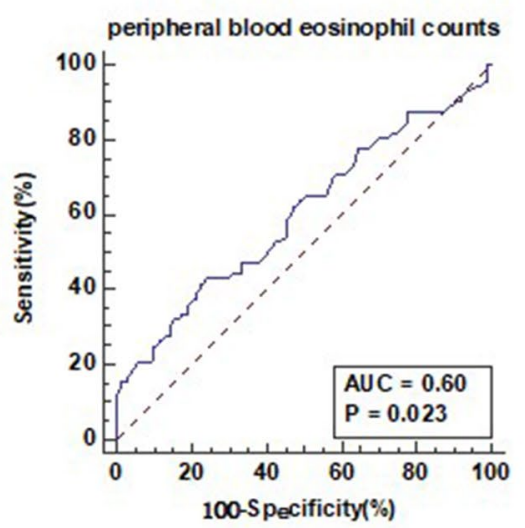

$\mathrm{F}$

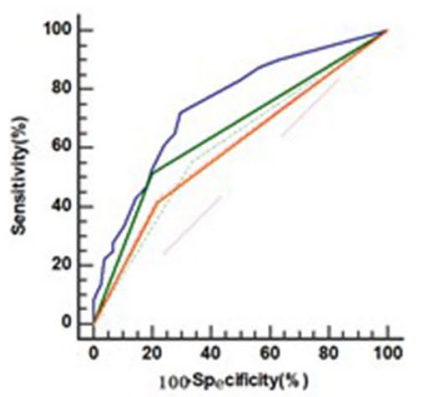

combined model

post bronchodilator FEV1\% predicted $\leq 71.40 \%$

peripheral blood eosinophil counts $>0.60 \times 10 \mathrm{e} / \mathrm{L}$ NPs

$\geq 1$ severe exacerbation in the last 12 months

Fig. 3 (See legend on previous page.) 
Table 4 Differential diagnostic values of postbronchodilator $\mathrm{FEV}_{1} \%$ predicted, peripheral blood eosinophil counts and combined model in detecting bronchiectasis in asthma-CRS overlap patients

\begin{tabular}{lllll}
\hline Items & Cutoff value & Sensitivity (\%) & Specificity (\%) & Youden index \\
\hline postbronchodilator FEV $\%$ predicted, $\%$ & 71.40 & 51.39 & 79.81 & 0.31 \\
peripheral blood eosinophil counts, $\times 10^{9} / \mathrm{L}$ & 0.60 & 41.67 & 77.88 & 0.20 \\
combined model & 0.33 & 72.22 & 70.19 & 0.42 \\
\hline
\end{tabular}

$F E V_{1}$ forced expiratory volume in $1 \mathrm{~s}$

Table 5 Univariate analyses of correlated factors for Smith scores in bronchiectasis patients

\begin{tabular}{|c|c|c|c|}
\hline \multirow[t]{2}{*}{ Variables } & \multicolumn{3}{|c|}{ Smith Score } \\
\hline & $r$ & $95 \% \mathrm{Cl}$ & $P$ value \\
\hline Male sex & 0.04 & -1.53 to 1.62 & 0.955 \\
\hline Age & 0.01 & -0.05 to 0.07 & 0.760 \\
\hline BMI & -0.18 & -0.35 to 0.00 & 0.049 \\
\hline Positive smoking status ${ }^{a}$ & 0.90 & -0.75 to 2.56 & 0.280 \\
\hline Smoking index ${ }^{b}$ & 0.19 & -0.23 to 0.59 & 0.367 \\
\hline Duration of asthma & 0.01 & -0.04 to 0.06 & 0.620 \\
\hline NPS & 1.35 & -0.21 to 2.90 & 0.088 \\
\hline Prior sinus surgery & 0.22 & -1.60 to 2.04 & 0.811 \\
\hline Allergic rhinitis & -0.37 & -2.06 to 1.31 & 0.662 \\
\hline Atopic dermatitis & -1.75 & -5.67 to 2.16 & 0.375 \\
\hline Gastroesophageal reflux disease & -0.12 & -3.21 to 2.98 & 0.941 \\
\hline ICS dose (fluticasone equivalent) & 0.00 & 0.00 to 0.00 & 0.812 \\
\hline Severe asthma & 0.82 & -1.10 to 2.75 & 0.397 \\
\hline $\begin{array}{l}\geq 1 \text { severe exacerbation of asthma in } \\
\text { the last } 12 \text { months }\end{array}$ & 1.14 & -0.43 to 2.70 & 0.153 \\
\hline$\geq 1$ pneumonia in the last 12 months & 1.40 & -0.23 to 3.04 & 0.091 \\
\hline Peripheral blood eosinophil count & 0.86 & -0.33 to 2.05 & 0.153 \\
\hline FeNO & 0.01 & -0.01 to 0.03 & 0.274 \\
\hline Total lgE & 0.00 & 0.00 to 0.00 & 0.476 \\
\hline Atopy & -0.98 & -2.54 to 0.58 & 0.214 \\
\hline postbronchodilator $\mathrm{FEV}_{1} \%$ predicted & -0.03 & -0.07 to 0.00 & 0.051 \\
\hline LM scores & 0.10 & -0.02 to 0.22 & 0.117 \\
\hline
\end{tabular}

$B M I$ body mass index, NPs nasal polyps, FEV , forced expiratory volume in $1 \mathrm{~s}, I C S$ inhaled corticosteroid, FeNO fractional exhaled nitric oxide, IgE immunoglobulin E, LM Lund-Mackay

${ }^{\text {a }}$ Positive smoking status included ex- and current-smokers

${ }^{\mathrm{b}}$ Smoking history in patients with positive smoking status

(anti-eosinophilic, anti-neutrophilic, or both) based on the underlying heterogeneous airway/circulating inflammation pattern for bronchiectasis-asthma-CRS overlapping patients should be further studied. Moreover, one post hoc analysis of a randomized clinical trial showed that the presence of eosinophils can occur in bronchiectasis patients even without asthma [31]. Most likely, bronchiectasis itself can be divided into "eosinophilichigh" and "neutrophilic-high" inflammation patterns with different mechanisms, clinical characteristics and therapy strategies.

In the current study, we showed that overlapping with bronchiectasis in asthma-CRS patients had a higher proportion of $\geq 1$ severe exacerbation of asthma in the last 12 months and a lower predicted $\mathrm{FEV}_{1} \%$. This outcome indicated that patients with both disorders in the same airway generally showed a more severe disease subset and worse prognosis. In line with our studies, previous studies also showed that bronchiectasis was more likely to exist in severe asthma with frequent exacerbations $[6,11,32-34]$. Asthma overlapping with bronchiectasis represents a distinct disease subset with a poorer prognosis in terms of asthma exacerbations and resistance to current asthma treatment. Therefore, we suggest that although the exact causal relationship between radiological bronchiectasis and asthma-CRS is currently unclear, it is plausible to hypothesize that the predisposing airway infiltration of eosinophils in asthma-CRS patients may induce persistent airway inflammation, airway remodeling and mucus plug removal impairment, which further leads to the development of bronchiectasis. Thus, bronchiectasis can impair lung function and induce frequent exacerbations of asthma and eventually promote the production of a specific disease subset associated with worse prognosis. However, how bronchiectasis and asthmaCRS overlap arise (i.e., a causal connection or a chance association) should be further investigated.

Generally, CRS can be divided into CRS with NPs (CRSwNPs) and CRS without NPs (CRSsNPs) based on the presence or absence of NPs. In contrast with CRSsNPs, CRSwNPs is mostly dominated by eosinophilic inflammation [3]. Our study showed that the presence and severity of radiological bronchiectasis was associated with NP occurrence (Tables 3 and 7). In line with our study, Canonica et al. also demonstrated that bronchiectasis was more common in patients with CRSwNPs than in those with CRSsNPs [2]. In view of this finding, the overlap of asthma, CRSwNPs, and bronchiectasis in the same airway may represent a distinct disease subset with eosinophilic airway inflammation instead of neutrophils. Thus, targeted therapy for CRSwNP patients, e.g., ICS, anti-allergic drugs, and polypectomy, may also be beneficial for patients with overlapping radiological 

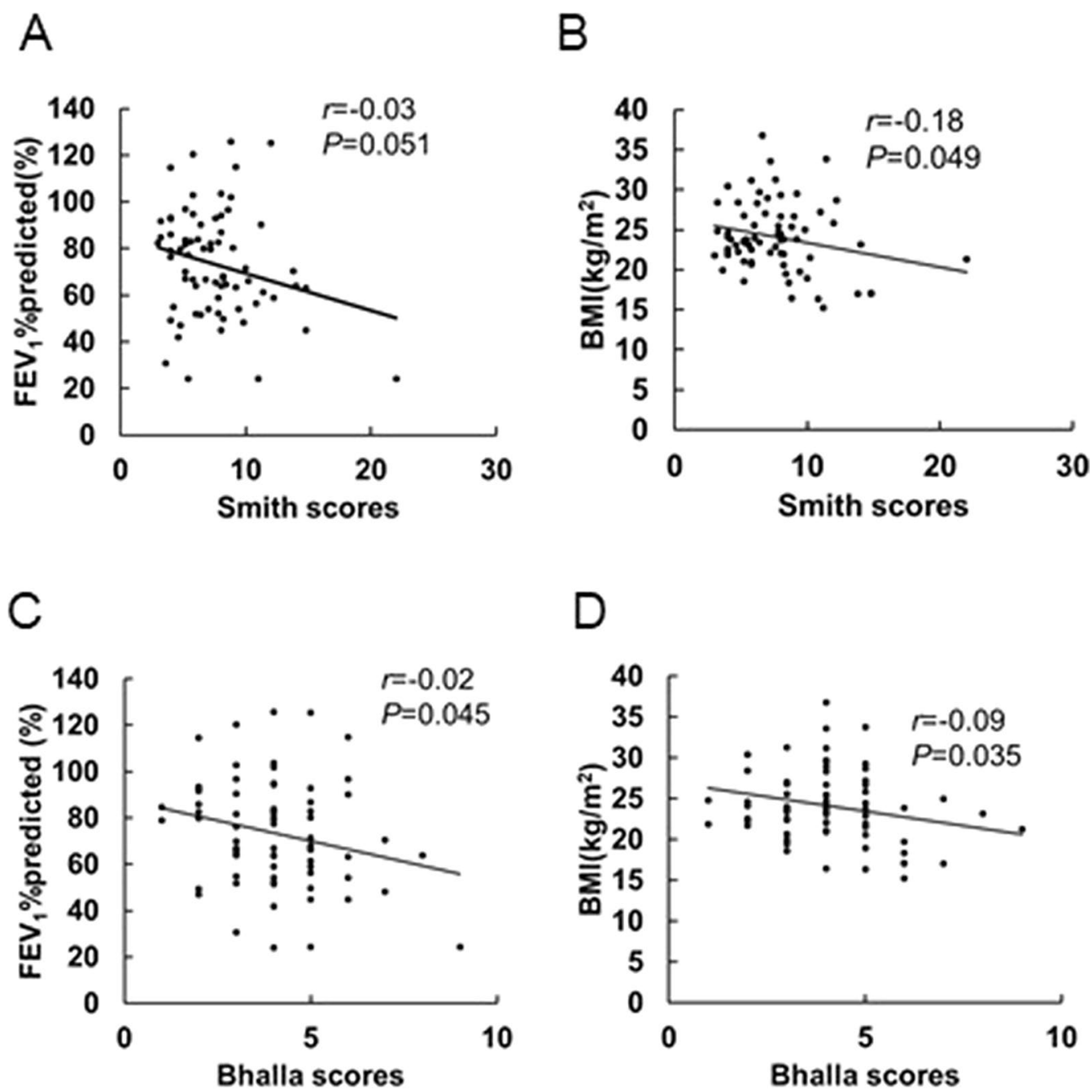

Fig. 4 Correlation analysis in the bronchiectasis group. A Scatter plot between Smith scores and postbronchodilator FEV $\%$ predicted. B Scatter plot between Smith scores and BMI. C Scatter plot between Bhalla scores and postbronchodilator FEV $\%$ predicted. D Scatter plot between Bhalla scores and BMI

bronchiectasis. However, the definite causal relationship between CRSwNPs and radiological bronchiectasis in the context of unified airway eosinophilic inflammation is currently unclear. Large cohort, long-term, and followup studies using patients with CRSwNPs and radiological bronchiectasis alone or overlapping are needed to resolve this open question.

Comprising all of the above, we established a combined model to predict the presence of bronchiectasis from asthma-CRS patients, with postbronchodilator $\mathrm{FEV}_{1} \%$ predicted $\leq 71.40 \%$, peripheral blood eosinophil counts $>0.60 \times 10^{9} / \mathrm{L}$, the presence of NPs, and $\geq 1$ severe exacerbation of asthma in the last 12 months. It is recommended to perform chest HRCT to monitor and intervene in bronchiectasis early, especially for asthma-CRS patients with these characteristics.

Our findings showed that the BMI of patients with asthma-CRS bronchiectasis decreased as the degree of bronchiectasis deteriorated. Similarly, previous studies also indicated that bronchiectasis can lead to malnutrition with lower BMI in patients with asthma [35]. Bronchiectasis patients with a lower BMI were prone to develop more acute exacerbations, worse pulmonary function and higher risk of death because of amplified systemic inflammation and chronic bacterial colonization $[35,36]$. Taken together, our results suggest that the severity of bronchiectasis in asthma-CRS patients predicts a poor nutritional status and quality of life and should be surveilled and treated. 
Table 6 Univariate analyses of correlated factors for Bhalla scores in bronchiectasis patients

\begin{tabular}{|c|c|c|c|}
\hline \multirow[t]{2}{*}{ Variables } & \multicolumn{3}{|c|}{ Bhalla score } \\
\hline & $r$ & $95 \% \mathrm{Cl}$ & $P$ value \\
\hline Male sex & 0.19 & -0.54 to 0.92 & 0.602 \\
\hline Age & 0.01 & -0.01 to 0.04 & 0.368 \\
\hline $\mathrm{BMl}$ & -0.09 & -0.17 to -0.01 & 0.035 \\
\hline Positive smoking status ${ }^{a}$ & 0.75 & 0.00 to 1.50 & 0.050 \\
\hline Smoking index ${ }^{\mathrm{b}}$ & 0.08 & -0.12 to 0.27 & 0.429 \\
\hline Duration of asthma & -0.00 & -0.03 to 0.02 & 0.811 \\
\hline NPs & 0.81 & 0.10 to 1.51 & 0.026 \\
\hline Prior sinus surgery & 0.02 & -0.82 to 0.86 & 0.965 \\
\hline Allergic rhinitis & 0.06 & -0.72 to 0.84 & 0.876 \\
\hline Atopic dermatitis & -1.09 & -2.88 to 0.71 & 0.232 \\
\hline Gastroesophageal reflux disease & -0.69 & -2.11 to 0.73 & 0.335 \\
\hline ICS dose (fluticasone equivalent) & 0.00 & -0.00 to 0.00 & 0.468 \\
\hline Severe asthma & 0.62 & -0.26 to 1.50 & 0.164 \\
\hline $\begin{array}{l}\geq 1 \text { severe exacerbation of asthma } \\
\text { in the last } 12 \text { months }\end{array}$ & 0.27 & -0.46 to 1.00 & 0.469 \\
\hline $\begin{array}{l}\geq 1 \text { pneumonia in the last } \\
12 \text { months }\end{array}$ & 0.50 & -0.26 to 1.26 & 0.194 \\
\hline Peripheral blood eosinophil counts & 0.19 & -0.36 to 0.74 & 0.493 \\
\hline FeNO & 0.01 & 0.00 to 0.02 & 0.044 \\
\hline Total lgE & 0.00 & 0.00 to 0.00 & 0.468 \\
\hline Atopy & -0.30 & -1.03 to 0.42 & 0.408 \\
\hline $\begin{array}{l}\text { Postbronchodilator } \mathrm{FEV}_{1} \% \text { pre- } \\
\text { dicted }\end{array}$ & -0.02 & -0.03 to 0.00 & 0.045 \\
\hline LM scores & 0.05 & 0.00 to 0.11 & 0.060 \\
\hline
\end{tabular}

$B M /$ body mass index, NPs nasal polyps, FEV , forced expiratory volume in $1 \mathrm{~s}, I C S$ inhaled corticosteroid, FeNO fractional exhaled nitric oxide, IgE immunoglobulin E, LM Lund-Mackay

${ }^{a}$ Positive smoking status included ex- and current-smokers

${ }^{\mathrm{b}}$ Smoking history in patients with positive smoking status
Several previous studies have described the adverse effects of smoking on asthma and CRS [37, 38], and similarly, smoking was an independent risk factor for the severity and prognosis of bronchiectasis [39]. Our study also demonstrated that there was a positive correlation between the severity of bronchiectasis and positive smoking status. Thus, smoking cessation in asthma-CRS patients is strongly advised, especially in patients with overlapping bronchiectasis.

\section{Limitations}

There were several limitations in this study. First, this is a clinical study. Further study on the molecular mechanism may provide a basis to explore the pathogenesis of the asthma-CRS-bronchiectasis subset. Second, this study involved asthmatic patients with stable status, and further research focusing on inflammatory characteristics during the exacerbation of asthma may more fully evaluate the relationship of bronchiectasis and asthma-CRS with different stages. Third, due to a lack of microbiological information, the role of infection in the presence and development of bronchiectasis in asthma-CRS needs further investigation. Last, as this is a single-center study with a limited sample size, external validation, such as a multicenter study or study of other races, needs to be carried out to verify the conclusion.

\section{Conclusions}

The coexistence of radiographic bronchiectasis in asthma-CRS patients is common and predicts a distinct disease subset with more severe eosinophilic airway inflammation, more serious asthma and CRS, and lower

Table 7 Multivariate linear regression analyses for Smith scores and Bhalla scores

\begin{tabular}{|c|c|c|c|}
\hline \multirow[t]{2}{*}{ Variables } & \multicolumn{3}{|c|}{ Smith score: multivariate linear regression } \\
\hline & $\beta$ coefficients & $95 \% \mathrm{Cl}$ & $P$ value \\
\hline NPs & 1.74 & 0.25 to 3.24 & 0.023 \\
\hline Postbronchodilator $\mathrm{FEV}_{1} \%$ predicted & -0.04 & -0.07 to -0.01 & 0.019 \\
\hline BMl & -0.18 & -0.34 to -0.01 & 0.041 \\
\hline \multirow[t]{2}{*}{ Variables } & \multicolumn{3}{|c|}{ Bhalla score: multivariate linear regression } \\
\hline & $\beta$ coefficients & $95 \% \mathrm{Cl}$ & $P$ value \\
\hline NPs & 1.11 & 0.45 to 1.77 & 0.001 \\
\hline Postbronchodilator $\mathrm{FEV}_{1} \%$ predicted & -0.02 & -0.03 to -0.00 & 0.029 \\
\hline BMI & -0.08 & -0.16 to -0.01 & 0.032 \\
\hline Positive smoking status ${ }^{a}$ & 0.73 & 0.03 to 1.44 & 0.042 \\
\hline
\end{tabular}

BMI body mass index, $F E V$, forced expiratory volume in $1 \mathrm{~s}, N P s$ nasal polyps

a Positive smoking status included ex- or current-smokers 
quality of life. Subgroups of asthma-CRS patients with NPs, more severely impaired lung function, higher circulating levels of eosinophils, and more frequent acute asthma attacks should receive HRCT examination for earlier diagnosis and treatment of bronchiectasis.

\section{Abbreviations}

CRS: Chronic rhinosinusitis; LM: Lund-Mackay; HRCT: High-resolution CT; NPs: Nasal polyps; GINA: Global Initiative for Asthma; FEV : Forced expiratory volume in one second; COPD: Chronic obstructive pulmonary disease; IgE: Immunoglobulin E; FeNO: Fraction of exhaled nitric oxide; FVC: Forced vital capacity; ROC: Receiver operating characteristic; AUC: Area under the curve.

\section{Acknowledgements}

We acknowledge Dr. Shuling Li and Dr. Qinghua Chen of the Department of Radiology of Beijing Tongren Hospital for the HRCT and paranasal sinus CT analysis.

\section{Authors' contributions}

HS designed the study, performed the data analysis and drafted the manuscript. XY reviewed and edited the manuscript. XW performed data acquisition. $Y W$ performed data acquisition. $X L$ designed the study, administered the project, and reviewed and edited the manuscript. $L Z$ provided supervision and project administration. All authors read and approved the final manuscript.

\section{Funding}

This work was supported by grants from the National Natural Science Foundation of China (81800014) and the Beijing Natural Science Foundation (7212018)

\section{Availability of data and materials}

The datasets used and analyzed for this study are available from the corresponding author on reasonable request.

\section{Declarations}

\section{Ethics approval and consent to participate}

This study complied with the Declaration of Helsinki and was approved by the Ethics Committee of Beijing Tongren Hospital, Capital Medical University (Approval Number: TRECKY2013-KS-37). Written informed consent was obtained from all recruited patients.

\section{Consent for publication}

Not applicable.

\section{Competing interests}

The authors declare that they have no competing interests.

\section{Author details}

${ }^{1}$ Department of Respiratory and Critical Care Medicine, Beijing Tongren Hospital, Capital Medical University, No. 1, Dongjiao Minxiang, Dongcheng District, Beijing 100730, China. ${ }^{2}$ Department of Otolaryngology Head and Neck Surgery, Beijing Tongren Hospital, Capital Medical University, Beijing, China. ${ }^{3}$ Key Laboratory of Otolaryngology Head and Neck Surgery of Ministry of Education of China, Beijing Institute of Otolaryngology, No. 17, Hougou Hutong, Dongcheng District, Beijing 100005, China.

Received: 25 March 2021 Accepted: 24 June 2021

Published online: 05 July 2021

\section{References}

1. Kim HY, So YK, Dhong HJ, Chung SK, Choi DC, Kwon NH, et al. Prevalence of lower airway diseases in patients with chronic rhinosinusitis. Acta
Otolaryngol Suppl. 2007;558:110-4. https://doi.org/10.1080/0365523070 1624988.

2. Canonica GW, Malvezzi L, Blasi F, Paggiaro P, Mantero M, Senna G, et al. Chronic rhinosinusitis with nasal polyps impact in severe asthma patients: evidences from the Severe Asthma Network Italy (SANI) registry. Respir Med. 2020;166: 105947. https://doi.org/10.1016/j.rmed.2020. 105947.

3. Fokkens WJ, Lund VJ, Hopkins C, Hellings PW, Kern R, Reitsma S, et al. European position paper on rhinosinusitis and nasal polyps 2020. Rhinology. 2020;58(S29):1-464. https://doi.org/10.4193/Rhin20.600.

4. Ek A, Middelveld RJM, Bertilsson H, Bjerg A, Ekerljung L, Malinovschi $A$, et al. Chronic rhinosinusitis in asthma is a negative predictor of quality of life: results from the Swedish GA(2)LEN survey. Allergy. 2013;68:1314-21. https://doi.org/10.1111/all.12222.

5. Polverino E, Goeminne PC, McDonnell MJ, Aliberti S, Marshall SE, Loebinger MR, et al. European Respiratory Society guidelines for the management of adult bronchiectasis. Eur Respir J. 2017;50:1700629. https://doi.org/10.1183/13993003.00629-2017.

6. Coman I, Pola-Bibian B, Barranco P, Vila-Nadal G, Dominguez-Ortega J, Romero D, et al. Bronchiectasis in severe asthma: clinical features and outcomes. Ann Allergy Asthma Immunol. 2018;120(4):409-13. https:// doi.org/10.1016/j.anai.2018.02.016.

7. Chen FJ, Liao H, Huang XY, Xie CM. Importance of fractional exhaled nitric oxide in diagnosis of bronchiectasis accompanied with bronchial asthma. J Thorac Dis. 2016;8(5):992-9. https://doi.org/10.21037/jtd. 2016.03.72.

8. Boaventura R, Sibila O, Agusti A, Chalmers JD. Treatable traits in bronchiectasis. Eur Respir J. 2018;52(3):1801269. https://doi.org/10.1183/ 13993003.01269-2018.

9. Mao B, Yang JW, Lu HW, Xu JF. Asthma and bronchiectasis exacerbation. Eur Respir J. 2016;47(6):1680-6. https://doi.org/10.1183/13993003. 01862-2015.

10. Porsbjerg C, Menzies-Gow A. Co-morbidities in severe asthma: clinical impact and management. Respirology. 2017;22(4):651-61. https://doi. org/10.1111/resp.13026.

11. Perez-Miranda J, Traversi L, Polverino E. Bronchiectasis in severe asthma: a distinct phenotype? Curr Opin Pulm Med. 2019;25(1):71-8. https://doi. org/10.1097/MCP.0000000000000542.

12. Guilemany JM, Angrill J, Alobid I, Centellas S, Pujols L, Bartra J, et al. United airways again: high prevalence of rhinosinusitis and nasal polyps in bronchiectasis. Allergy. 2009;64(5):790-7. https://doi.org/10.1111/j.1398-9995. 2008.01892.x.

13. Somani SN, Kwah JH, Yeh C, Conley DB, Grammer LC, Kern RC, et al. Prevalence and characterization of chronic rhinosinusitis in patients with non-cystic fibrosis bronchiectasis at a tertiary care center in the United States. Int Forum Allergy Rhinol. 2019;9(12):1424-9. https://doi.org/10. 1002/alr.22436.

14. Handley E, Nicolson CH, Hew M, Lee AL. Prevalence and clinical implications of chronic rhinosinusitis in people with bronchiectasis: a systematic review. J Allergy Clin Immunol Pract. 2019;7(6):2004-12. https://doi.org/ 10.1016/j.jaip.2019.02.026.

15. Padilla-Galo A, Olveira C, Fernandez de Rota-Garcia L, Marco-Galve I, Plata AJ, Alvarez A, et al. Factors associated with bronchiectasis in patients with uncontrolled asthma; the NOPES score: a study in 398 patients. Respir Res. 2018;19(1):43. https://doi.org/10.1186/s12931-018-0746-7.

16. Shteinberg M, Nassrallah N, Jrbashyan J, Uri N, Stein N, Adir Y. Upper airway involvement in bronchiectasis is marked by early onset and allergic features. ERJ Open Res. 2018;4:1. https://doi.org/10.1183/23120541. 00115-2017.

17. Ramakrishnan VR, Ferril GR, Suh JD, Woodson T, Green TJ, Kingdom TT. Upper and lower airways associations in patients with chronic rhinosinusitis and bronchiectasis. Int Forum Allergy Rhinol. 2013;3(11):921-7. https://doi.org/10.1002/alr.21204.

18. Global Initiative for Asthma. Global strategy for asthma management and prevention. 2020. www.ginasthma.org

19. American Thoracic S, European RS. ATS/ERS recommendations for standardized procedures for the online and offline measurement of exhaled lower respiratory nitric oxide and nasal nitric oxide, 2005. Am J Respir Crit Care Med. 2005;171(8):912-30. https://doi.org/10.1164/rccm 200406-710ST. 
20. Miller MR, Hankinson J, Brusasco V, Burgos F, Casaburi R, Coates A, et al. Standardisation of spirometry. Eur Respir J. 2005;26(2):319-38. https://doi. org/10.1183/09031936.05.00034805.

21. Pasteur MC, Bilton D, Hill AT. British Thoracic Society Bronchiectasis non CFGG. British Thoracic Society guideline for non-CF bronchiectasis. Thorax. 2010;65(Suppl 1):i1-58. https://doi.org/10.1136/thx.2010.136119.

22. Smith IE, Jurriaans E, Diederich S, Ali N, Shneerson JM, Flower CDR. Chronic sputum production: correlations between clinical features and findings on high resolution computed tomographic scanning of the chest. Thorax. 1996;51(9):914-8. https://doi.org/10.1136/thx.51.9.914.

23. Lynch DA, Newell JD, Tschomper BA, Cink TM, Newman LS, Bethel R. Uncomplicated asthma in adults: comparison of CT appearance of the lungs in asthmatic and healthy subjects. Radiology. 1993;188(3):829-33. https://doi.org/10.1148/radiology.188.3.8351357.

24. Bhalla M, Turcios N, Aponte V, Jenkins M, Leitman BS, McCauley DI, et al. Cystic fibrosis: scoring system with thin-section CT. Radiology. 1991;179(3):783-8. https://doi.org/10.1148/radiology.179.3.2027992.

25. Lund VJ, Kennedy DW. Staging for rhinosinusitis. Otolaryngol Head Neck Surg. 1997;117(3 Pt 2):S35-40. https://doi.org/10.1016/s0194-5998(97) 70005-6.

26. Hanley JA, MCNeil BJ. A method of comparing the areas under receiver operating characteristic curves derived from the same cases. Radiology. 1983;148(3):839-43. https://doi.org/10.1148/radiology.148.3.6878708.

27. Hamilos DL. Chronic rhinosinusitis: epidemiology and medical management. J Allergy Clin Immunol. 2011;128(4):693-707. https://doi.org/10. 1016/j.jaci.2011.08.004.

28. Inoue $\mathrm{H}$, Ito I, Niimi A, Matsumoto $\mathrm{H}$, Matsuoka $\mathrm{H}$, Jinnai $\mathrm{M}$, et al. CTassessed large airway involvement and lung function decline in eosinophilic asthma: the association between induced sputum eosinophil differential counts and airway remodeling. J Asthma. 2016;53(9):914-21. https://doi.org/10.3109/02770903.2016.1167903.

29. Kim S, Lee CH, Jin KN, Cho SH, Kang HR. Severe asthma phenotypes classified by site of airway involvement and remodeling via chest CT scan. J Investig Allergol Clin Immunol. 2018;28(5):312-20. https://doi.org/10. 18176/jiaci.0265.

30. Lujan M, Gallardo X, Amengual MJ, Bosque M, Mirapeix RM, Domingo C. Prevalence of bronchiectasis in asthma according to oral steroid requirement: influence of immunoglobulin levels. Biomed Res Int. 2013;2013: 109219. https://doi.org/10.1155/2013/109219.
31. Martinez-Garcia MA, Posadas T, Sotgiu G, Blasi F, Saderi L, Aliberti S. Repeteability of circulating eosinophil measures and inhaled corticosteroids effect in bronchiectasis. A post hoc analysis of a randomized clinical trial. Arch Bronconeumol. 2020;56:681-3. https://doi.org/10.1016/j.arbres. 2020.06.005.

32. Garcia-Clemente M, Enriquez-Rodriguez Al, Iscar-Urrutia M, EscobarMallada B, Arias-Guillen M, Lopez-Gonzalez FJ, et al. Severe asthma and bronchiectasis. J Asthma. 2020;57(5):505-9. https://doi.org/10.1080/ 02770903.2019 .1579832$.

33. Crimi C, Ferri S, Campisi R, Crimi N. The link between asthma and bronchiectasis: state of the art. Respiration. 2020;99(6):463-76. https://doi.org/10. $1159 / 000507228$.

34. Kang HR, Choi GS, Park SJ, Song YK, Kim JM, Ha J, et al. The effects of bronchiectasis on asthma exacerbation. Tuberc Respir Dis (Seoul). 2014;77(5):209-14. https://doi.org/10.4046/trd.2014.77.5.209.

35. Li L, Li Z, Bi J, Li H, Wang S, Shao C, et al. The association between serum albumin/prealbumin level and disease severity in non-CF bronchiectasis. Clin Exp Pharmacol Physiol. 2020;47(9):1537-44. https://doi.org/10.1111/ 1440-1681.13331.

36. Qi Q, LiT, Li JC, Li Y. Association of body mass index with disease severity and prognosis in patients with non-cystic fibrosis bronchiectasis. Braz J Med Biol Res. 2015;48(8):715-24. https://doi.org/10.1590/1414-431X2 0154135.

37. Shi JB, Fu QL, Zhang H, Cheng L, Wang YJ, Zhu DD, et al. Epidemiology of chronic rhinosinusitis: results from a cross-sectional survey in seven Chinese cities. Allergy. 2015;70(5):533-9. https://doi.org/10.1111/all.12577.

38. likura M, Hojo M, Koketsu R, Watanabe S, Sato A, Chino H, et al. The importance of bacterial and viral infections associated with adult asthma exacerbations in clinical practice. PLoS ONE. 2015;10(4): e0123584. https://doi.org/10.1371/journal.pone.0123584.

39. Sin S, Yun SY, Kim JM, Park CM, Cho J, Choi SM, et al. Mortality risk and causes of death in patients with non-cystic fibrosis bronchiectasis. Respir Res. 2019;20(1):271. https://doi.org/10.1186/s12931-019-1243-3.

\section{Publisher's Note}

Springer Nature remains neutral with regard to jurisdictional claims in published maps and institutional affiliations.
Ready to submit your research? Choose BMC and benefit from:

- fast, convenient online submission

- thorough peer review by experienced researchers in your field

- rapid publication on acceptance

- support for research data, including large and complex data types

- gold Open Access which fosters wider collaboration and increased citations

- maximum visibility for your research: over $100 \mathrm{M}$ website views per year

At BMC, research is always in progress.

Learn more biomedcentral.com/submissions 